\section{AB1183 DIAGNOSTIC VALUE OF SALIVARY CRP AND IL-6 IN PATIENTS UNDERGOING ANTI-TNF-ALPHA THERAPY FOR RHEUMATIC DISEASE}

D. Sikorska, R. Rutkowski, A. Prymas, M. Mrall-Wechta, D. Bednarek-Hatlińska, A. Surdacka, W. Samborski, J. Witowski. Poznan University of Medical Sciences, Poznan, Poland

Background: Saliva has been increasingly used as a diagnostic medium for disease detection and monitoring. Since saliva contains many of mediators of inflammation, collagen breakdown and/or bone remodelling, they may be of potential use for the rheumatic disease monitoring. ${ }^{1,2}$

Objectives: The aim of this pilot study was to investigate whether and how well salivary concentrations of CRP and IL- 6 correlate with those in serum and with the clinical course of a rheumatic disease.

Methods: The nineteen consenting patients with rheumatoid arthritis or ankylosing spondylitis, newly scheduled for anti-TNF $\alpha$ therapy, were analysed. CRP and IL- 6 were measured with high-sensitivity immunoassays before and after 12 weeks of anti-TNF $\alpha$ therapy, according to standard regimens. Disease activity and oral health parameters were also assessed.

Results: The patients' baseline characteristics were summarised in Table 1.

Abstract AB1183 - Table 1. Patients' baseline characteristics

\begin{tabular}{lc}
\hline Demographic and clinical features & \\
\hline Age (years) & $46(36-61)$ \\
\hline Men (\%) & $10(53 \%)$ \\
Oral health parameters & \\
Plaque Index (PLI) & $0.7(0.4-1.0)$ \\
Approximal Plaque Index (API) (\%) & $75.0(42.9-100.0)$ \\
Sulcus Bleeding Index (SBI) & $0.0(0.0-0.3)$ \\
Gingival Index (GI) & $0.4(0.0-1.0)$ \\
Probing Pocket Depth (PD) (mm) & $0.8(0.6-1.3)$ \\
Clinical Attachment Level (CAL) & $1.4(0.6-2.0)$ \\
DMFT index & $18.5(15.0-26.0)$ \\
\hline
\end{tabular}

The treatment resulted in a significant improvement in the clinical status and standard biochemical parameters in the majority of patients (table 2).

Abstract AB1183 - Table 2. Selected parameters before and after treatment.

\begin{tabular}{lccc}
\hline & $\begin{array}{c}\text { Before treatment } \\
(\mathbf{n}=\mathbf{1 9})\end{array}$ & $\begin{array}{c}\text { After 12 weeks of treatment } \\
(\mathbf{n}=\mathbf{1 9})\end{array}$ & $\begin{array}{c}\text { P-value } \\
\text { (Wilcoxon- } \\
\text { test) }\end{array}$ \\
\hline DAS28 $_{(\mathrm{ESR})}($ for $R A ;$ & $6.2(5.5-6.4)$ & $3.5(2.8-4.5)$ & $\mathbf{0 . 0 0 5}$ \\
$n=10)$ & & & \\
BASDAI (for AS; $n=9)$ & $7.9(6.6-8.6)$ & $2.8(2.0-4.2)$ & $\mathbf{0 . 0 0 8}$ \\
ESR $(\mathrm{mm} / \mathrm{h})$ & $30(8-70)$ & $6(4-24)$ & $\mathbf{0 . 0 0 2}$ \\
WBC $\left(10^{3} / \mathrm{l}\right)$ & $9.3(8.2-9.9)$ & $8.0(6.4-9.7)$ & $\mathbf{0 . 0 1 5}$ \\
Serum CRP $(\mathrm{mg} / \mathrm{l})$ & $10.24(4.65-24.31)$ & $1.52(0.54-4.13)$ & $\mathbf{0 . 0 1 0}$ \\
Serum IL-6 $(\mathrm{pg} / \mathrm{ml})$ & $14.23(5.03-34.61)$ & $2.32(1.49-25.14)$ & $\mathbf{0 . 0 4 4}$ \\
Salivary CRP $(\mathrm{mg} / \mathrm{l})$ & $0.30(0.02-3.72)$ & $0.05(0.00-1.87)$ & 0.098 \\
Salivary IL-6 $(\mathrm{pg} / \mathrm{ml})$ & $1.91(0.94-2.43)$ & $1.48(0.98-2.78)$ & 0.811 \\
\hline
\end{tabular}

Concentrations of CRP in saliva correlated significantly with those in serum $(R=0.62 ; p<0.001)$ and decreased markedly after successful response to treatment $(n=15)(1.7 \pm 0.2 .2 \mathrm{mg} / \mathrm{L}$ vs. $0.8 \pm 1.4 \mathrm{mg} / \mathrm{L} ; \mathrm{p}<0.001)$. In patients with a limited or no response to treatment $(n=4)$ salivary CRP levels increased $(0.4$ $\pm 0.8 \mathrm{mg} / \mathrm{L}$ vs. $2.6 \pm 2.4 \mathrm{mg} / \mathrm{L} ; \mathrm{p}=0.250$ ).

In contrast to CRP, the salivary concentrations of IL-6 did not change significantly over the course of therapy and they did not correlate with serum IL-6 concentrations. Salivary levels of neither CRP nor IL-6 corresponded to parameters of oral health and hygiene.

Conclusions: These data indicate, that salivary CRP but not IL-6 could be of potential use for monitoring the rheumatic disease activity.

\section{REFERENCES :}

[1] Buczko P, Zalewska A, Szarmach I. Saliva and oxidative stress in oral cavity and in some systemic disorders. Journal of physiology and pharmacology: an official journal of the Polish Physiological Society. 2015;66 (1):3-9.

[2] Mirrielees J, Crofford LJ, Lin Y, Kryscio RJ, Dawson DR, 3rd, Ebersole JL, et al. Rheumatoid arthritis and salivary biomarkers of periodontal disease. Journal of clinical periodontology. 2010;37(12):1068-74.

Disclosure of Interest: None declared

DOI: 10.1136/annrheumdis-2018-eular.1547

\section{$\mathrm{AB} 1184$ \\ CORRELATION BETWEEN CLINICAL DISEASE ACTIVITY AND SACROILIAC MRI DETECTION IN AXIAL SPONDYLOARTHROPATHY}

O. Inan ${ }^{1}$, N. sayiner caglar ${ }^{1}$, Y. pekin dogan ${ }^{1}$, I.N. mutlu ${ }^{2}$, K. aydemir ${ }^{1}$, N. oz ${ }^{1}$, E. aytekin ${ }^{1} .{ }^{1}$ physical medicine and rehabilitation; ${ }^{2}$ radiology, health of sciences istanbul training and research hospital, istanbul, Turkey

Background: Ankylosing spondylitis (AS), a chronic rheumatic disease affecting young adults, is the prototype of the seronegative spondyloarthropathies (SpA). Magnetic resonance imaging (MRI) has an established role in the diagnosis and monitoring of patients with axial spondyloarthropaties (axSpA). Changes in MRI have shown some correlation with changes in clinical disease activity scores in the setting of biologic trials. MRI of the sacroiliac joints (SIJ) is currently widely used to assess inflammatory activity in AS patients. In general, agreement of status scores was somewhat better than agreement of change scores, and agreement of the comprehensiveSpondyloarthritis Research Consortium of Canada scoring system (SPARCC) was somewhat better than agreement of the more condensed systems.

Objectives: The aim of this study is to evaluate the correlation between clinical disease activity of axSpA and MRI findings of sacroiliac joints.

Methods: Patients who were diagnosed as axSpA according to the Assessment of SpondyloArthritis international Society(ASAS) classification criteria in the our outpatient clinic and followed up routinely between November 2015 and August 2017 were included in this study. 32 patients between 18 and 55 years of age had been referred for routine blood tests and sacroiliac MRI. In this cross-sectional study, VAS, BASDAI, MASES, BASFI, ASDAS-ESR, ASDAS-CRP, ESR and CRP were used as the indicators of clinical activity. MRI of the sacroiliac joint was performed and the SPARCC score was evaluated by a radiologist who was blind to the clinical and laboratory parameters of the patients.

Results: The mean age of the patients was $39.3 \pm 9.2$. 11 of the patients participating in the study were female $(34.4 \%), 21$ were male $(65.6 \%)$. The mean duration of symptom onset was $9.3 \pm 7.7$ years and the mean duration of diagnosis was 3.6 \pm 2.8 years. $\mathrm{HLA}-\mathrm{B} 27$ is positive in 16 patients $(\% 50)$. There is no correlation between SPARCC score and VAS, BASDAI, MASES, BASFI, ASDAS-CRP, ASDAS-ESR, ESR, CRP values ( $p>0.05$ ). In the HLA-B27 subgroup analyses, a statistically significant correlation was found between HLA-B27 negative patients and SPARCC score $(\mathrm{p}=0.008)$.

Conclusions: As a result of this study, we could not find any relationship between other clinical disease parameters and sacroiliac joint imaging findings except for SPARCC score relationship with BASDAI in HLA-B27 negative patients with axSpA. We think that this relationship can be better revealed in future studies.

\section{REFERENCES:}

[1] Zhang P, Yu K, Guo R, Shah S, Morelli JN, Runge VA, Li X.Ankylosing spondylitis: correlations between clinical and MRI indices of sacroiliitis activity.Clin Radiol. 2015 Jan;70(1):62-6. doi: 10.1016/j.crad.2014.09.015. Epub 2014 Oct 22.

[2] MacKay JW, Aboelmagd S, Gaffney JK.Correlation between clinical and MRI disease activity scores in axial spondyloarthritis.Clin Rheumatol. 2015 Sep;34(9):1633-8. doi: 10.1007/s10067-015-2936-8. Epub 2015 Apr 19.

[3] Landewé RB, Hermann KG, van der Heijde DM, Baraliakos X, Jurik AG, Lambert RG, Østergaard M, Rudwaleit M, Salonen DC, Braun J. Scoring sacroiliac joints by magnetic resonance imaging. A multiple-reader reliability experiment.J Rheumatol. 2005 Oct;32(10):2050-5.

Disclosure of Interest: None declared

DOI: 10.1136/annrheumdis-2018-eular.1221

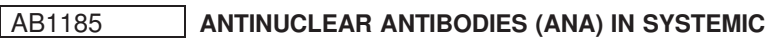 LUPUS ERYTHEMATOSUS (SLE): ASSOCIATIONS WITH CLINICAL MANIFESTATIONS AND CYTOKINE PROFILES}

E. Aleksandrova ${ }^{1}$, A. Novikov ${ }^{1}$, Z. Verizhnikova ${ }^{2}$, T. Panafidina ${ }^{2}$, T. Popkova ${ }^{2}$, G. Lukina'. ${ }^{1}$ A.S. Loginov Moscow Clinical Research and Practical Center, Moscow Healthcare Department, ${ }^{2}$ V.A. Nasonova Research Institute of Rheumatology, Moscow, Russian Federation

Background: SLE is a multisystem heterogeneous autoimmune disease charac terised by production of antibodies to cellular components, innate and adaptive immune alterations and dysregulation of cytokine production. Multiplex immunoassay is a useful tool for the detection of ANA associated with different clinica phenotypes and cytokine profiles in SLE.

Objectives: To evaluate the relationship between ANA subpopulations, clinical subtypes and cytokine profiles in SLE.

Methods: We studied 61 patients with SLE (2012 SLICC classification criteria) (8M/ $53 \mathrm{~F})$, median and interquartile range (25th - 75th percentile) of age 30.0 (27.0 45.0) years, disease duration 90.5 (12.5-168.0) months, SLEDAI 2K score 8.0 